\title{
The role of a Drosophila POU homeo domain gene in the specification of neural precursor cell identity in the developing embryonic central nervous system
}

\author{
Xiaohang Yang, Suling Yeo, Thomas Dick, and William Chia ${ }^{1}$ \\ Drosophila Neurobiology Laboratory, Institute of Molecular and Cell Biology, National University of Singapore, \\ Singapore 0511
}

\begin{abstract}
The Drosophila embryonic central nervous system (CNS) is derived from a stereotypic array of progenitor stem cells called neuroblasts (NBs). Each of the $\sim 25 \mathrm{NBs}$ per hemisegment undergoes repeated asymmetric divisions to produce, on average, 5-10 smaller ganglion mother cells (GMCs); each GMC, in turn, divides to produce two neurons. We demonstrate that the protein product encoded by a POU homeo domain gene (dPOU28/pdm-2) is expressed in the cell nuclei of a subset of NBs and GMCs. In the wild-type animal, GMC-1 is the only identified cell in the NB4-2 lineage that expresses dPOU28 protein to a high level, and it divides to produce the RP2 neuron and a second cell of unknown fate. Our results suggest that the presence of ectopically induced dPOU $28 / \mathrm{pdm}-2$ protein in the progeny of GMC-1 is sufficient to cause both of these cells to adopt their parental GMC-1 cell fate, leading to duplication of the RP2 neuron (and its sister cell) on the basis of both immunological and morphological criteria. These observations clearly implicate a role for dPOU28/pdm-2 in the specification of GMC-1 cell identity in the NB4-2 lineage and possibly in the specification of cell fate in other NB lineages in the developing embryonic CNS.
\end{abstract}

[Key Words: POU homeo domain gene; Drosophila; embryonic CNS; neural precursor cells]

Received August 24, 1992; revised version accepted January 4, 1993.

The formation of the Drosophila nervous system is dependent on a complex network of interacting developmental regulators. To rationalize the roles played by these regulators, the process of neurogenesis can be conceptually divided into two discrete categories of events: (1) the events leading to the formation of the neuronal progenitor cells, the neuroblasts (NBs) for the central nervous system (CNS) and the sensory mother cells (SMCs) for the peripheral nervous system (PNS) (for review, see Ghysen and Dambly-Chaudiere 1989; CamposOrtega 1990; Jan and Jan 1991; Campuzano and Modolell 1992); and (2) the events that specify the unique fate of each of the neuronal progenitor cells and each of their progeny (for review, see Doe 1992a).

A generally accepted perspective is that the anterior/ posterior and dorsal/ventral pattern formation genes act to define a region of the ventral ectoderm, the neurogenic region, from where CNS precursors separate from the epidermal precursors (see Doe 1992). Following gastrulation, through the combined actions of the family of proneural genes for which all of the characterized members, for example, daughterless and the achaete-scute

${ }^{1}$ Corresponding author. complex, encode basic helix-loop-helix transcription factors (Villares and Cabrera 1987; Caudy et al. 1988), $\sim 2000$ ectodermal cells from the ventral neurogenic region acquire the potential to become neuronal precursors. However, only $\sim 25 \%$ of these cells enlarge and delaminate from the ectoderm to form NBs; each of the forming NBs, through the actions of the family of neurogenic genes (e.g., Notch; for review, see Artavanis-Tsakonas and Simpson 1991), laterally inhibit their neuroectodermal neighbors and prevent them from also becoming NBs. In this way the combined actions of the proneural genes and the neurogenic genes act to ensure the formation of $\sim 25 \mathrm{NBs}$ per hemisegment. However, the available data suggest that the neurogenic and the proneural genes do not play a role in specifying the identity of neuronal progenitor cells (Jimenez and CamposOrtega 1990; Rodrigues et al. 1990; Martin-Bermudo et al. 1991).

The NBs undergo a series of asymmetric divisions to produce, on average, 5-10 ganglion mother cells (GMCs), each of which divides to generate two neurons; studies on the grasshopper have led to the conclusion that each NB gives rise to a unique cell lineage, forming a characteristic family of neurons specific to that NB. The same is assumed for Drosophila because its nervous system is 
highly homologous to that of the grasshopper (Thomas et al. 1984). However, in contrast to the grasshopper, NB lineages are not topologically distinct in Drosophila; and partial lineage information is available only for a few NBs (Doe et al. 1988a; Doe 1992a).

The identification of candidate genes that act to specify the unique identities of each of the NBs and their progeny GMCs and neurons has started only recently. Although a number of previously identified genes (Blochlinger et al. 1990; Mlodzik et al. 1990; DamblyChaudiere et al. 1992), many of which act in pattern formation (e.g., Carroll and Scott 1985; Frasch et al. 1987; Gaul et al. 1987; Schroder et al. 1988; Hooper and Scott 1989; Nakano et al. 1989; Patel et al. 1989a; van den Heuvel et al. 1989; Kania et al. 1990; for review, see Doe and Smouse 1990; Doe 1992a), appear to have a later phase of expression in the nervous system, a functional role in nervous system development has not been demonstrated for many of them. In addition, a number of genes have been identified that are necessary for the development of identified neurons in the CNS (Rothberg et al. 1988; Thomas et al. 1988; Patel et al. 1989a; Finkelstein et al. 1990; Klambt et al. 1991); however, their involvement in the specification of CNS cell fate is unclear. The two homeo box-containing pair-rule genes fushi tarazu (ftz) and even-skipped (eve) have loss-offunction phenotypes and expression patterns consistent with a role in the specification of GMC identity (Doe et al. 1988a,b); the pair-rule gene runt is apparently required for the identity of the neuroblast, which gives rise to EL neurons (Duffy et al. 1991); the phenotype of lossof-function alleles of the homeo box gene prospero (pros) and its RNA expression pattern are consistent with it having a role in specifying NB identity (Doe et al. 1991). However, pros protein has not yet been found in NBs (Vaessin et al. 1991). At least two genes, cut (Bodmer et al. 1987; Blochlinger et al. 1991) and pox neuro (DamblyChaudiere et al. 1992), function in the PNS in a way that is analogous to "NB identity genes"; these genes act to specify the identity of SMCs. Owing to the better defined lineage relationships for the PNS cell types, several other genes encoding putative transcription factors have been identified that specify cell fate at various levels of embryonic PNS development (for review, see Jan and Jan 1991).

To understand the generation of neuronal diversity in the CNS, the genes that act to specify neural precursor cell fate must first be defined. We and others (Billin et al. 1991; Dick et al. 1991; Lloyd and Sakonju 1991) have reported the isolation of the POU domain (Herr et al. 1988) genes, $d P O U 28 / p d m-2$ and $d P O U 19 / p d m-1$, whose transcripts accumulate in the developing CNS and PNS. Here, we assess the functional role of $d P O U 28 / p d m-2$ in CNS development. We present evidence for a specific and defined cell fate transformation in the developing embryonic CNS leading to the duplication of the RP2 neuron, which is caused by the ectopic expression of $d P O U 28 / p d m-2$. In addition, we have raised antibody that specifically recognizes the $d P O U 28 / p d m-2$ protein and show that this protein is expressed in a subset of NBs and GMCs /including GMC-1 of NB4-2). Our results indicate that dPOU28/ $p d m-2$ acts to specify the cell fate of GMC-1 in the NB4-2 lineage; its ectopic expression in the two progeny cells of GMC-1 is sufficient to cause both of these cells to adopt a GMC-1 cell identity. We discuss these results within the context of Drosophila CNS development and in light of biological functions defined for POU domain genes isolated from other organisms.

\section{Results \\ Organization of $\mathrm{dPOU} 28 / \mathrm{pdm}-2$ and the generation of germ-line transformants carrying a HSP70/dPOU28 transgene}

Previously, we and others have reported the sequence of twoDrosophila genes, dPOU28/pdm-2 and dPOU19/ $p d m-1$, with POU domains that are highly homologous to the mammalian Oct-1 and Oct-2 transcription factors (Billin et al. 1991; Dick et al. 1991; Lloyd and Sakonju 1991). On the basis of their RNA expression patterns, we proposed a possible role for these genes in the determination of cell fate during the development of the embryonic CNS. Here, we test this assertion by examining the phenotypic consequences of ectopic expression of $d P O U 28 / p d m-2$. The genomic organization of $d P O U 28 /$ $p d m-2$ is shown in Figure 1a. A construct in which the expression of a full-length $d P O U 28 / p d m-2$ cDNA was placed under the control of the $H S P 70$ promoter was made (Fig. 1b; also see Materials and methods), and germ-line transformants homozygous for a single third chromosome insertion of the HSP70/dPOU28 transgene were generated (data not shown). We show that dPOU28 protein accumulates ubiquitously in the cell nuclei of heat-shocked transgenic animals (Fig. 1c).

\section{Ectopic expression of $\mathrm{dPOU} 28 / \mathrm{pdm}-2$ causes duplication of the RP2 neuron}

Following heat shock during the early stages of embryonic CNS development, we looked for alterations in the pattern of previously identified neurons in the CNS using an array of antibody markers, including anti-engrailed (en) (Patel et al. 1989b), anti-ftz (gift from the Gehring laboratory, Brozentrumn, Basel, Switzerland), and anti-eve (Frasch et al. 1987). We did not observe any obvious alterations in the anti-en and anti-ftz patterns (data not shown). But with anti-eve we detected an alteration in the lineage of NB4-2, one of the few NBs for which a partial lineage (Fig. 2a) has been described (Doe et al., 1988b; Doe 1992a,b) and for which a number of antibody markers are available (see Fig. 2). In wild-type animals, the neurons produced by the first two GMC progeny are marked. GMC-1 expresses both $\mathrm{ftz}$ and eve and divides to produce the RP2 neuron and a second cell of unknown fate; both RP2 and its sister cell express eve; the evidence for the GMC-1 lineage has been documented convincingly (Doe 1992b). GMC-2 expresses ftz, and Doe (1992a) has suggested that it divides to produce the RP1 and RP3 neurons, both of which are marked by 

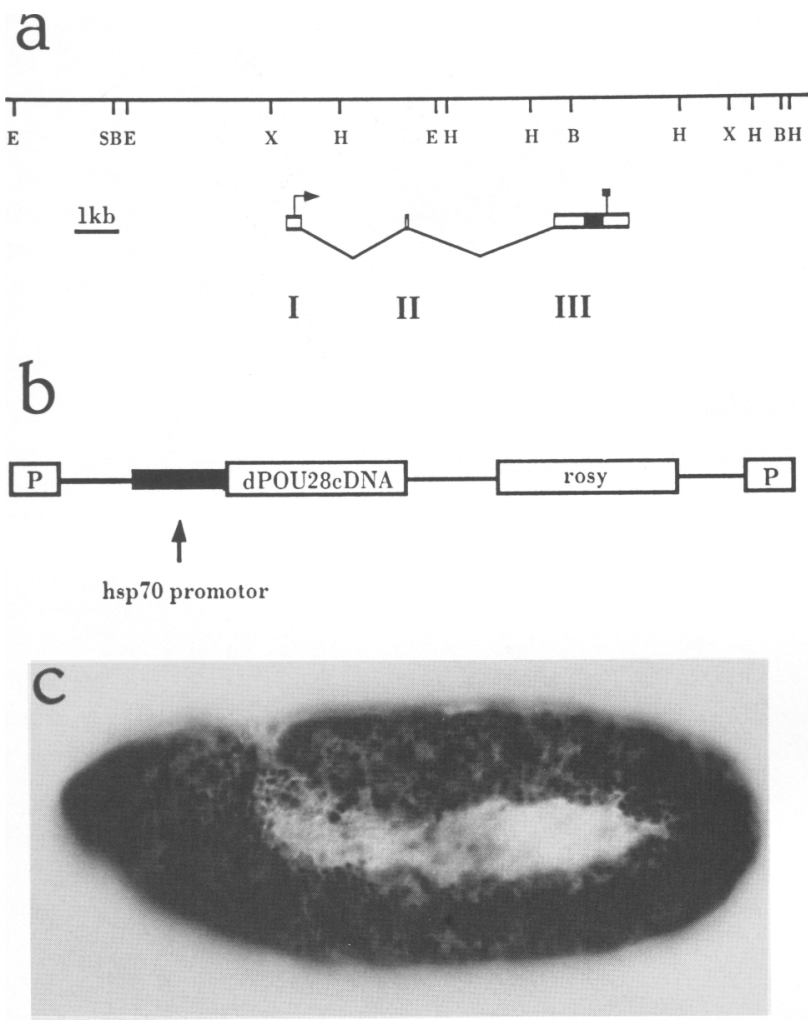

Figure 1. The $d P O U 28 / p d m-2$ gene and the HSP7O/dPOU28 construct. (a) A 20-kb genomic region encompassing dPOU28/ $p d m-2$ is represented by the top line. The organization of the 8-kb primary transcript derived by comparing the cDNA sequence with genomic sequences spanning the intron-exon junctions is shown. The precise location of the 57-bp exon II has not been determined. The initiation codon is indicated by the arrow; the stop codon, by a solid square; the POU domain is filled in. (E) EcoRI; (S) SalI; (B) BamHI; (X) XhoI; (H) HindIII. (b) Diagram of the HSP70/dPOU28 construct (see Materials and methods). (c)Lateral view of a stage 11 transformant stained with anti-dPOU28 90 min after heat shock; anterior is left and dorsal is at top.

mAb2D5, which recognizes fasciclin III (Patel et al. 1987, 1989a). In a large proportion of the germ-line transformants heat-shocked at stage 11 (all staging according to Campos-Ortega and Hartenstein 1985) and then allowed to develop, we observe two eve-positive neurons per hemisegment at or near the position of the RP2 neuron (at stages 12 or later; see Fig. 3c), whereas only one RP2 neuron is present in wild-type controls or non-heatshocked animals homozygous for the HSP7O/dPOU28 transgene (Fig. 3a). For transformants heat-shocked during the correct temporal window (see below); $>95 \%$ of the animals exhibit duplication of the eve-positive cell at the RP2 position in at least one thoracic hemisegment; up to $63 \%(144 / 228)$ of the thoracic hemisegments examined exhibit duplication of this eve-positive cell. These putative RP2 duplications are also observed for the abdominal segments; however, they occur at a greatly reduced frequency.

To ascertain whether both of the eve-positive cells oc- cupying the RP2 position have characteristics consistent with an RP2 cell identity, we stained heat-shocked transformants with an additional antibody, anti-DPTP99A, which recognizes a Drosophila tyrosine phosphatase that is known to be expressed on the cell body of RP2 early during its development (Yang et al. 1991). Consistent with an RP2 cell identity, both of these eve-positive cells are stained by anti-DPTP99A (not shown). To determine whether these cells have morphological characteristics consistent with an RP2 cell identity, heatshocked animals were allowed to develop to stages when axon morphology can be more clearly observed. These embryos were double labeled with anti-eve, which marks the RP2 nucleus and mAb22C10 (Fujita et al. 1982; Zipursky et al. 1984), a monoclonal antibody that stains the cell bodies and axons of a subset of CNS neurons including the RP2 neurons. Both of these eve-positive cells appear to send axons toward the ipsilateral intersegmental nerve (Fig. 3d) like the wild-type RP2 neuron (Fig. 3b). Hence, on the basis of both antigenic and morphological criteria, it appears that the RP2 neuron is duplicated in heat-shocked animals carrying the HSP70/ POU28 transgene.

\section{Duplication of RP2 is not caused by duplication of NB4-2}

The two most likely explanations for the observed duplication of the RP2 neuron resulting from the ectopic expression of $d P O U 28 / p d m-2$ are: (1) NB4-2 is duplicated, or (2) some cell fate transformation has occurred within the NB4-2 lineage. The first possibility can be ruled out. If duplication of NB4-2 is the explanation, we would expect to see duplications of other identified neurons in the NB4-2 lineage (e.g., duplication of RP1 and RP3) in hemisegments where RP2 is duplicated. This possibility was tested by double-labeling heat-shocked and non-heat-shocked embryos with anti-eve (labels the RP2 nucleus) and mAb2D5, which recognizes fasciclin III (stains RP1 and RP3 cell bodies and axons; the RP2 cell body is stained at stage 12 but not in later stages; see legend to Fig. 4). In heat-shocked embryos, within those hemisegments in which two RP2 neurons are present, only one RP1 and one RP3 neuron are observed (Fig. 4b); however, the positions of the RP1 and RP3 neurons appear abnormal. In wild-type animals, RP3 is located directly ventral to RPl, whereas in the hemisegments in which RP2 is duplicated, RP1 and RP3 appear almost on the same plane of focus (see legend to Fig. 4). Nevertheless, these results argue against the duplication of NB4-2 as the cause for the observed RP2 duplication.

It is important to note that the conclusion against NB duplication is not dependent on knowing the GMC-2 lineage of NB4-2 because the temporal window during which ectopically expressed protein is required also precludes NB4-2 duplication as the cause of the RP2 duplication (see section on temporal considerations and Discussion, below). Therefore, the most likely cause for the observed RP2 duplication is a change in cell fate within the GMC-1 lineage (see below). 

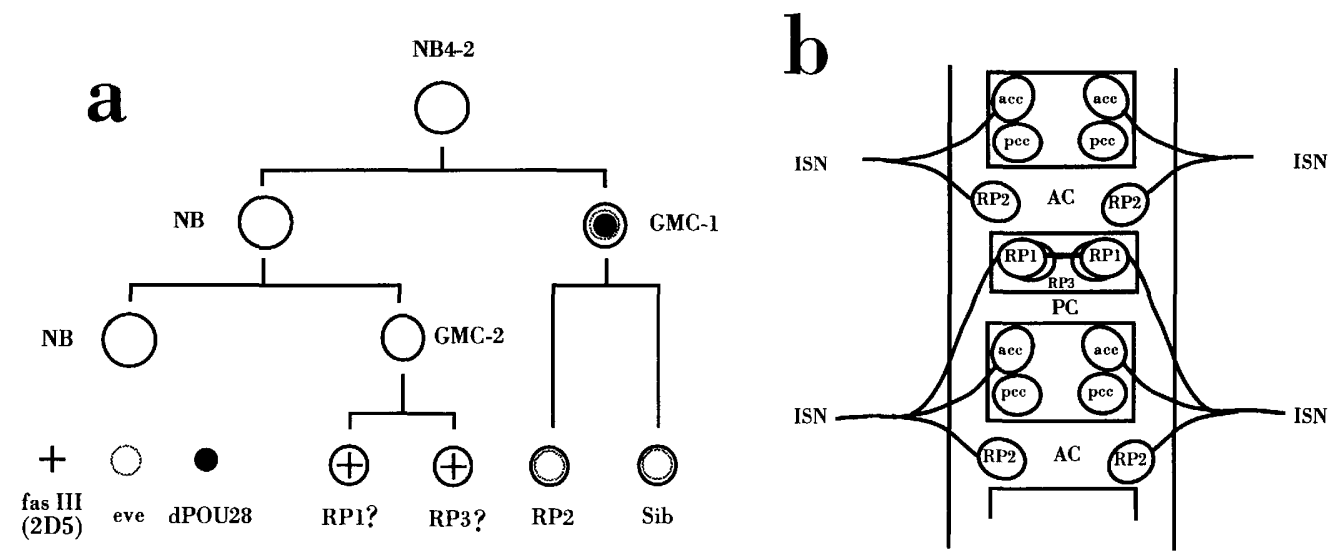

Figure 2. The proposed partial lineage of NB4-2 and the final positions of its identified neuronal progeny. (a) In wild-type embryos GMC-1 divides to produce the RP2 neuron and a sibling cell of unknown fate; eve protein is expressed in GMC-1 and its progeny. It has been suggested (Doe 1992a) that GMC-2 divides to produce the RP1 and RP3 neurons both of which express fasciclin III (recognized by mAb2D5). Both GMC-1 and GMC-2 and their progeny express ftz. (b) The final positions of RP1, RP2 (eve + ), RP3, aCC (eve + ), and pCC (eve + ) neurons are diagramed schematically. The axons of RP2 and aCC join the ipsilateral intersegmental nerve (ISN); the axons of RP1 and RP3 join the contralateral ISN. (AC) Anterior commissure; (PC) posterior commissure.

Ectopic expression of dPOU $28 / \mathrm{pdm}-2$ causes

the progeny cells of GMC-1 to adopt a GMC-1 fate within the NB4-2 lineage

In wild-type animals GMC-1 divides to produce RP2 and a sister cell of unknown fate (Doe 1992b). There are at least two plausible rationalizations for the observed duplication of RP2 involving cell fate transformations within the GMC-1 lineage (also see Discussion): (1) The sister cell of RP2 now adopts the fate of RP2 and develops into a second eve-positive neuron, or (2) the two progeny of GMC-1 rather than developing into RP2 and its sister, now both adopt the fate of GMC-1. A comparison of the kinetics of appearance of eve-expressing cells from the NB4-2 lineage in wild-type (Fig. 5a-d) and heatshocked animals (Fig. 5e-i) supports the latter possibility. In the wild-type NB4-2 lineage, the only identified GMC that expresses eve is GMC-1, and GMC-1 divides to generate two eve-positive cells, RP2 and its sister. When the kinetics of appearance of eve-positive cells is followed in the wild-type NB4-2 lineage (1) there is initially one labeled cell (GMC-1); (2) after GMC-1 divides, two labeled cells are observed; (3) eve expression fades from the RP2 sister cell (possibly because it is programmed to die) so that one labeled cell (RP2) plus one weakly labeled cell (RP2 sister cell) are observed; and, finally, (4) only one labeled cell (RP2) is observed following the cessation of eve expression by the RP2 sister cell (possibly caused by cell death).

The kinetics of appearance of $e v e$-labeled cells in heatshocked animals (see Fig. 5e-i) is what would be expected if the progeny of GMC-1 adopt the fate of GMC-1: (1) Initially, there is one labeled cell (GMC-1); (2) followed by the appearance of two labeled cells (the two converted GMC-1s); (3) four labeled cells are then observed lapparently because both GMC-ls divide to produce eve-positive daughters as in the wild-type situation); (4) followed by two labeled cells and two weakly labeled cells /the labeled cells being RP2s, and the weakly labeled cells being RP2 sisters; finally, $(5)$ two labeled cells are observed (the duplicated RP2s).

If the duplication of RP2 was the result of the sister of RP2 adopting the fate of RP2, at no time should four eve-positive cells be observed (near the RP2 location) following heat shock; because four labeled cells are observed, this possibility is unlikely. Moreover, the observed kinetics of appearance of eve-positive cells following heat shock clearly support the notion that the duplication of RP2 is the result of the generation of two cells with a GMC-1 identity. In addition, the physical proximity and the temporally synchronized appearance of the two eve-positive GMC-1s and their four eve-positive progeny following heat shock (see Fig. 5) strongly argue for the fact that the two GMC-1s are siblings; for example, if GMC-2 were to adopt a GMC-1 cell fate as a result of heat shock, one would expect the appearance of the two GMC-1s to be separated, temporally, by at least $30 \mathrm{~min}$ and one would not expect to observe the simultaneous appearance of two, followed by four, physically closely associated eve-positive cells as seen in Figure 5. These results and considerations lead us to conclude that the ectopic expression of $d P O U 28 / p d m-2$ causes both progeny of GMC-1 to adopt a GMC-1 cell fate (see Discussion).

Temporal considerations suggest that the observed cell fate transformations require the presence of ectopically expressed dPOU28/pdm-2 protein in the progeny cells of GMC-1

Our previous experiments have shown that a 10-min heat shock during stage 11 induced duplication of the RP2 neuron. We set out to determine more precisely the critical period during which heat shock is sufficient to effect the observed cell fate transformations. Because the 
Figure 3. Ectopic expression of dPOU28/ $p d m-2$ causes duplication of the RP2 neuron. $(a-d)$ Anterior is at top; the midline is indicated by broken lines; thoracic segments are shown; RP2s are indicated by arrows; aCC and pCC are indicated by arrowheads. (a) Dorsal view of a non-heatshocked stage 14 HSP70/dPOU28 embryo, dissected and stained with anti-eve. Note the presence of a single RP2 neuron (arrow) per hemisegment. (b) Same as $a$ but double-labeled with anti-eve (black nuclear staining) and $\mathrm{mAb} 22 \mathrm{Cl0}$ (brown, cell surface and axon staining); note that the eve-positive RP2 neuron (arrow) appears to send its axon toward the posterior root of the ipsilateral ISN (thin arrow). (c) Dorsal view of a heat-shocked HSP70/dPOU28 embryo dissected and stained with antieve. Note the presence of two eve-positive cells per hemisegment at the RP2 position (arrows). (d) Same as $c$ except double-labeled with anti-eve (black) and mAb22C10 (brown). Note that both of the eve-positive cells occupying the RP2 position appear to send axons toward the posterior root of the ipsilateral intersegmental nerve (ISN) (thin arrow). The eve-positive cells located near aCC (anterior arrowhead) and pCC (posterior arrowhead) are $\mathrm{CQ}$ neurons that normally lie ventral to $\mathrm{aCC}$ and pCC. Note that anti-eve stains three clusters of neurons, the aCC/pCC/CQ cluster, the EL cluster and RP2/RP2 sister cell /see Patel et al. 1989a); the position of RP2 and its progenitor are distinct from the other two clusters of stained cells. In this and all subsequent figures involving anti-eve staining, we focus only on RP2 and its relatives.

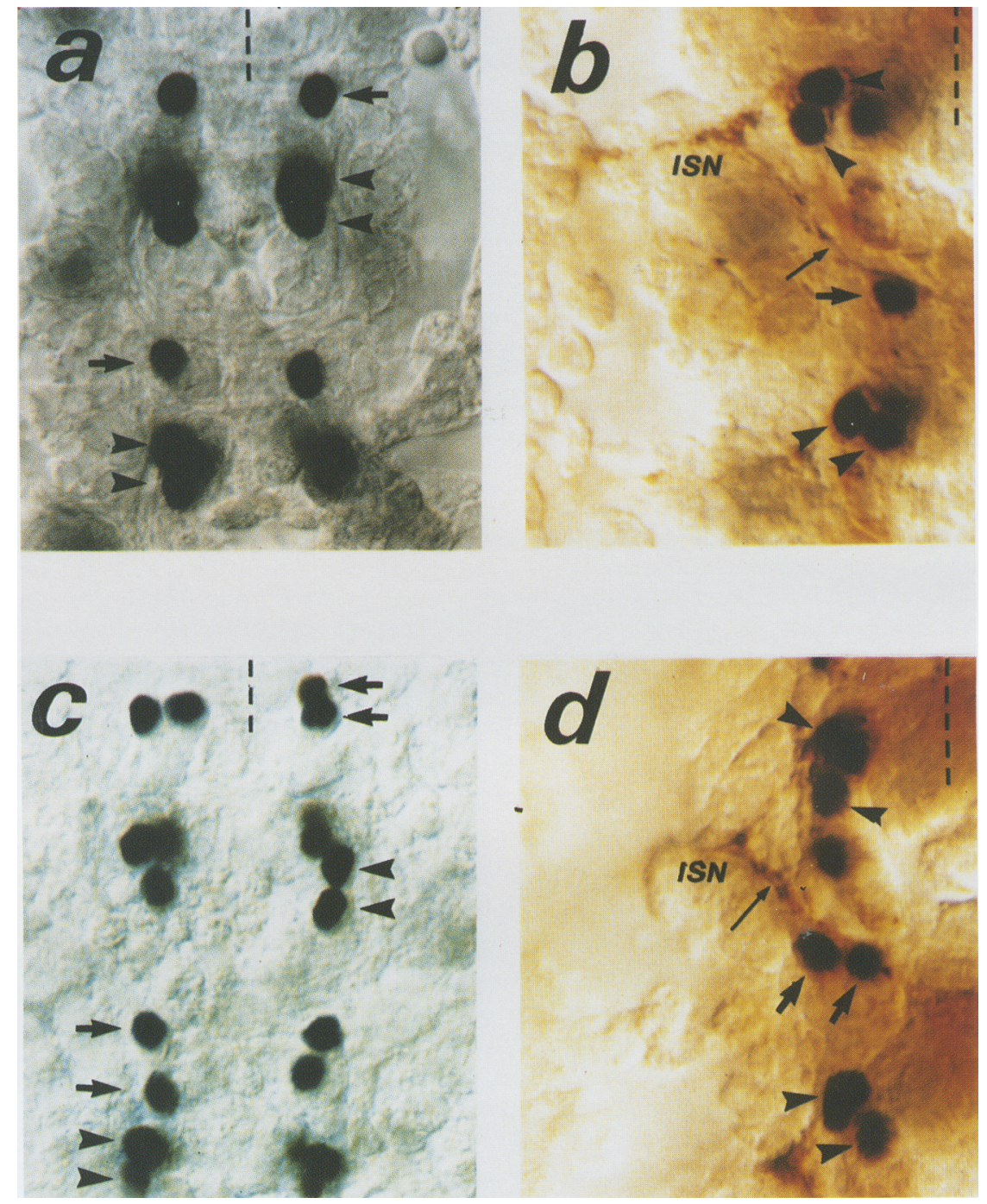

strains carrying the $H S P 70 / d P O U 28$ transgene have a slower rate of development than that of wild type, the time of heat shock is given relative to the time of appearance of the eve-positive GMC-1 and the time of GMC-1 division (see legend to Fig. 6). Half-hour embryo collections from the HSP70/dPOU28 homozygous transformants were aged for various periods of time before being submitted to a $10-\mathrm{min}$ heat shock at $37^{\circ} \mathrm{C}$. The heat-shocked embryos were aged and scored for duplication of RP2. The results, schematically summarized in Figure 6, indicate that a 10 min heat shock during a l-hr temporal window spanning the time of GMC-1 birth and GMC-1 division is sufficient to cause duplication of the RP2 neuron. However, heat-shocks before or after this temporal window do not cause RP-2 duplications at a significant frequency.

Two relevant pieces of information necessary for interpreting these results are the time lag between the time of heat shock and the appearance of (HSP70-driven) dPOU $28 / \mathrm{pdm}-2$ protein, as well as the stability of the ectopically expressed protein. Results of experiments in which embryos were exposed to a 10-min heat shock and then aged for various periods before being subjected to anti-dPOU28 staining indicate that accumulation of ectopically expressed $\mathrm{dPOU} 28 / \mathrm{pdm}-2$ protein reaches a maximal level 1-hr after heat-shock. High levels of protein accumulation persist until at least $2 \mathrm{hr}$ after heat shock (data not shown). Extrapolating from these results, a 10-min heat shock during the critical 1-hr window will lead to the accumulation of high levels of dPOU28/ pdm-2 protein in the nuclei of the progeny of GMC-1. These results are consistent with the notion that it is the presence of the ectopically expressed dPOU $28 / \mathrm{pdm}-2$ protein in the progeny of GMC-1 that causes these cells to adopt a GMC-1 cell fate.

GMC-1 is the only identified cell that expresses dPOU28/pdm-2 protein to a high level in the wildtype NB4-2 lineage

All of our previous results lead us to conclude that the presence of ectopically induced $\mathrm{dPOU} 28 / \mathrm{pdm}-2$ protein 


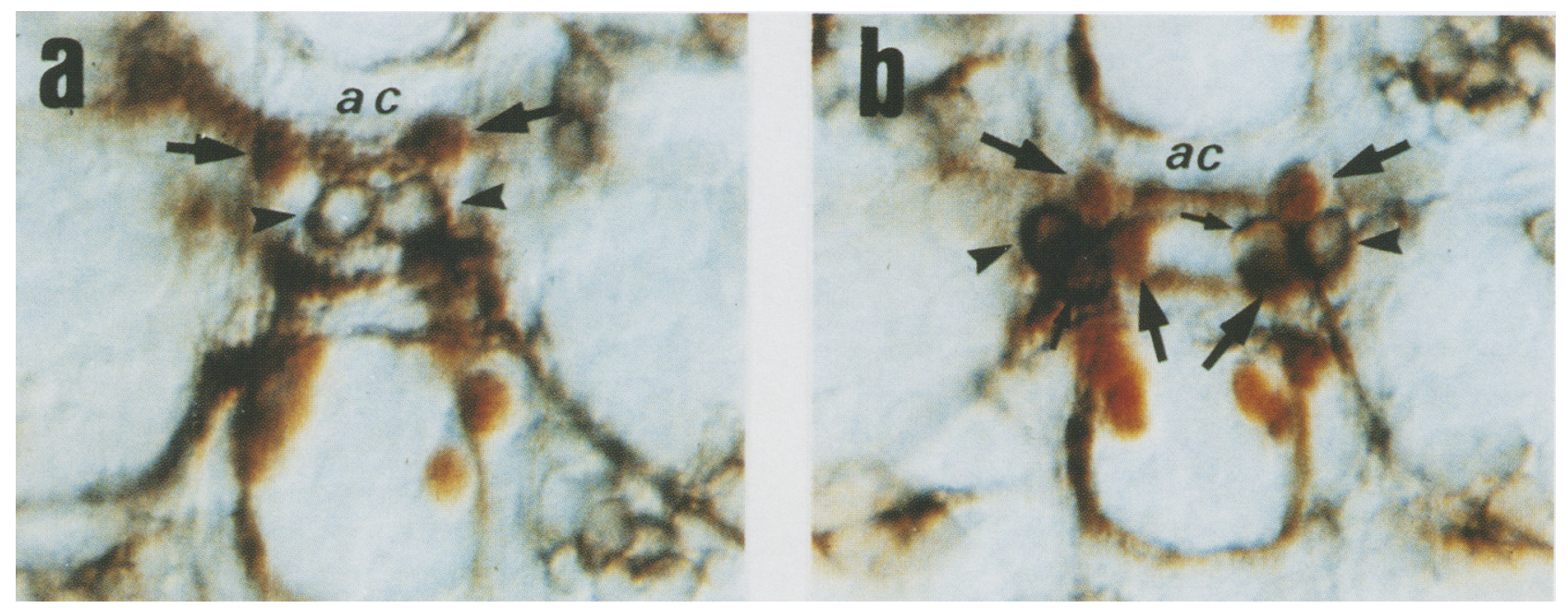

Figure 4. The number of RP1 and RP3 neurons is not affected by ectopic expression of $d P O U 28 / p d m-2$. (a) Dorsal view of a non-heat-shocked stage $14 \mathrm{HSP70/dPOU} 28$ embryo, dissected and double stained with anti-eve (brown) and mAb2D5 (black). At this stage, mAb2D5 stains RP1 and RP3, as well as the cells belonging to the ventrolateral and dorsolateral clusters (Patel et al. 1989a); only the cells in the vicinity of the RP cluster which is topologically distinct from the ventrolateral and dorsolateral clusters need to be considered here. Within the RP cluster, mAb2D5 stains the membrane of RP1 (arrowheads) and RP3 (located almost directly ventral to RP1 and not seen in this focal plane); 2D5 also weakly stains the RP2 cell body (at an earlier stage) and stains RP4 (at a later stage). Anti-eve stains RP2 nucleus (arrows). (b) Dorsal view of a heat-shocked stage 14 HSP70/dPOU28 embryo, dissected and double stained as in (a). The positions of RP1, RP3 (arrowheads and thin arrows, respectively) and RP2 (arrows) are indicated. Note that in $b$ two stained RP2s are present per hemisegment; in addition, RP1 and RP3 are present but displaced from their normal positions, possibly owing the presence of the extra RP2 (see text); our reason for designating these two cells RP1 and RP3 is because they are the only two cells strongly stained by mAb2D5 in the position of the RP cluster; however, we have not distinguished RP1 from RP3. It is also important to point out that in the vicinity of the RP cluster, we have also observed two additional cells ventral to RP1 that are weakly stained by mAb2D5, in agreement with Patel et al. (1989a). Although not seen in the plane of focus, these cells are present in both wild-type and heat-shocked transformant embryos of this stage. Therefore, the total number of mAb2D5-stained cells in the vicinity of the RP cluster (two strong and two weak) per hemisegment is the same in control hemisegments and in hemisegments showing the RP2 duplication, a result that is inconsistent with either duplication of RP1 and RP3 or the absence of RP1 and RP3. Anterior is at top; (ac) Anterior commissure.

in the progeny of GMC-1 is sufficient for these cells to adopt a GMC-1 cell fate. Implicit to this conclusion is that $d P O U 28 / p d m-2$ acts in the wild-type NB4-2 lineage to specify GMC-1 cell identity. These results and considerations predict that within the wild-type NB4-2 lineage, the $\mathrm{dPOU} 28 / \mathrm{pdm}-2$ protein should be expressed in GMC-1 but not its progeny.

To test this prediction, the $\mathrm{dPOU} 28 / \mathrm{pdm}-2$ protein expression pattern in the wild-type CNS was examined. Fusion protein containing a nonconserved region of the predicted dPOU $28 / \mathrm{pdm}-2$ protein (see Materials and methods) was used to generate polyclonal serum. The affinity-purified antibody specifically recognizes the dPOU $28 / \mathrm{pdm}-2$ protein as demonstrated by the observations that $(1)$ the protein expression patterns parallel the RNA expression patterns (not shown); (2) there is a lack of staining in animals deficient for the $d P O U 28 / \mathrm{pdm}-2$ gene (not shown); and (3) ubiquitous staining occurs in response to heat shock in transformants containing the HSP70/dPOU28 transgene (Fig. 1c). The staining observed with anti-dPOU28 is nuclear, as would be expected for most proteins containing DNA-binding motifs. In wild-type animals the antibody labels a subset of NBs and GMCs (Fig. 7).

Within the early part of the wild-type NB4-2 lineage, the only cell that expresses the $\mathrm{dPOU} 28 / \mathrm{pdm}-2$ protein to a high level is GMC-1; the criteria for making this assignment are by position (the GMC-1 of NB4-2 that stains is almost always directly dorsal to NB4-2; see Fig. 7 and legend) and by double-labeling experiments demonstrating that the $\mathrm{dPOU} / \mathrm{pdm}-2$ positive GMC-1 also expresses eve (data not shown). GMC-2, RP1, and RP3 do not express dPOU $28 / \mathrm{pdm}-2$ protein (data not shown). We have observed weak transient staining in newly divided GMC-1 progeny, which is at a greatly reduced level compared with the high levels present in GMC-1; we believe this weak staining is the result of the persistence of the $\mathrm{dPOU} 28 / \mathrm{pdm}-2$ protein present in GMC-1 and not its de novo synthesis in the GMC-1 progeny. Similarly, we have also seen occasional dPOU28/pdm-2-positive NB4$2 \mathrm{~s}$. They are always cells that have just delaminated into the NB layer; older NB4-2s do not stain. Because dPOU28/ $\mathrm{pdm}-2$ is expressed in the neuroectoderm, we believe that the occasional staining observed is the result of carryover of the protein synthesized before segregation of NB4-2.

\section{Discussion}

\section{A model for dPOU28/pdm-2 action}

We have shown that the ectopic expression of $d P O U 28 /$ 
Figure 5. The kinetics of appearance of eve-positive cells in the vicinity of NB4-2. $(a-d)$ Dorsal views of a temporal sequence of non-heat-shocked HSP70/dPOU28 embryos (from stage 11 to stage 14) stained with anti-eve. $(e-i)$ Dorsal views of a temporal sequence of heat-shocked HSP70/ dPOU28 embryos (stage 11 to stage 14) stained with anti-eve. Thoracic hemisegments are shown. The positions of GMC-1 and the postmitotic progeny of GMC-1 and RP2 are indicated by arrows. The position of the sibling of RP2, which transiently expresses eve, is indicated by arrowheads. The drawings below the panels represent our interpretation of the events taking place in the panels (see text). Anterior is at top; midline is to the right. The cluster of labeled cells, located posterior to GMC-1, RP2, and its sibling belong to the $\mathrm{aCC} / \mathrm{pCC} / \mathrm{CQ}$ cluster and their progenitors. A real rather than a plausible sequence of events is depicted in $a-i$ /see Materials and methods for criteria used for staging). It is representative of a sequence of events derived at by examining many embryos.
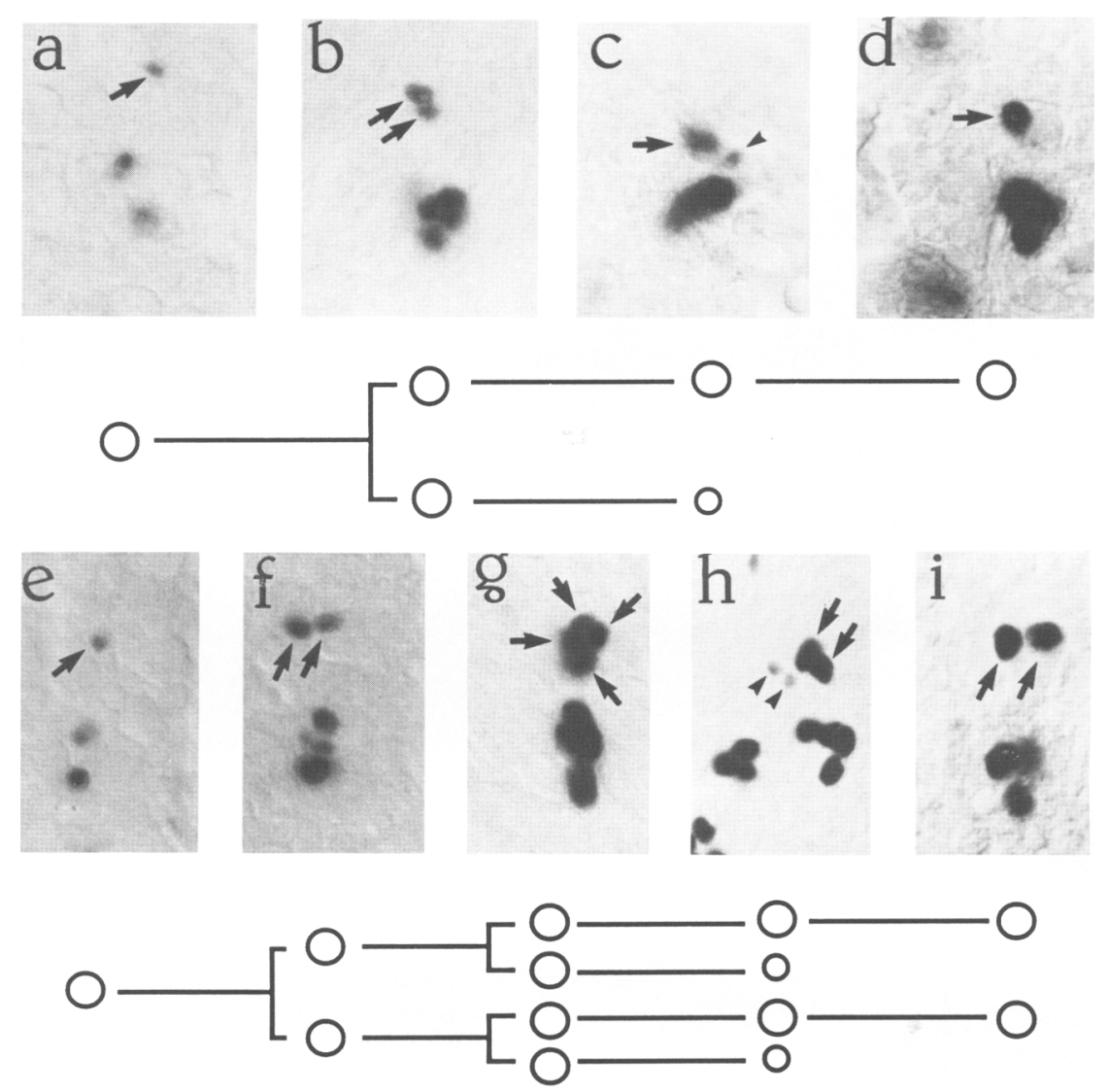

$p d m-2$ causes duplication of the RP2 neuron. The RP2 duplication is not caused by a duplication of NB4-2 because the RP1 and RP3 neurons, the putative progeny of GMC-2 in the NB4-2 lineage, are not duplicated; we stress that this conclusion is not dependent on knowing the GMC-2 lineage because the temporal window during which heat shock induces RP2 duplication also argues against duplication of NB4-2 as the cause of the RP2 duplication. By following the kinetics of appearance of eve-positive cells from the NB4-2 lineage in heatshocked transformant embryos, we observe two cells that exhibit characteristics consistent with a GMC-1 identity; they express eve; they divide to form two RP2 neurons and two cells that transiently express eve (sister of RP2). The temporally synchronized appearance and the close physical proximity of the two GMC-1s argue against (but do not preclude) the possibility that the second GMC-1 is caused by GMC-2 adopting the fate of GMC-1. The observed temporally synchronized appearance and physical proximity of the two GMC-1s suggest further that they are sibling cells. On the basis of these data, we conclude that as a result of $\mathrm{dPOU} 28 / \mathrm{pdm}-2 \mathrm{ec}-$ topic expression, the two progeny of GMC-1 adopt the identity of GMC-1. The temporal window during which heat shock is required for the observed cell fate transformations suggests that the presence of ectopically expressed dPOU $28 / \mathrm{pdm}-2$ protein in the progeny of GMC-1 is sufficient to cause these cells to adopt a
GMC-1 cell fate; consistent with this conclusion is the finding that in wild-type animals, the progeny of GMC-1 do not produce $\mathrm{dPOU} 28 / \mathrm{pdm}-2$ protein to an appreciable level. These results and considerations imply that the dPOU $28 / \mathrm{pdm}-2$ protein normally acts to specify GMC-1 identity in the NB4-2 lineage. This conclusion is supported by the finding that in the wild-type NB4-2 lineage, GMC-1 is the only cell identified that expresses $\mathrm{dPOU} / \mathrm{pdm}-2$ protein to a high level. A simple model that accounts for our results on the NB4-2 lineage following the ectopic expression of $d P O U 28 / p d m-2$ is represented schematically in Figure 8.

Although the results are consistent with our preferred model (Fig. 8), there are several possible alternative explanations that cannot be eliminated. First, it is possible that the observed cell fate transformations are not cell autonomous events triggered by the ectopic expression of $\mathrm{dPOU} 28 / \mathrm{pdm}-2$ protein in the progeny cells of GMC1; rather, the cell fate transformations caused by ectopic $\mathrm{dPOU} 28 / \mathrm{pdm}-2$ expression result from the disruption of normal cell-cell interaction events required for the development of the NB4-2 lineage. Although we cannot eliminate this possibility, results from both neuroblast ablation studies (Doe and Goodman 1985) and experiments using in vitro cultures of isolated Drosophila neuroblasts (Huff et al. 1989) indicate that the specification of the cell fate of the early GMCs is not affected by environmental influences or cell-cell interaction. Sec- 


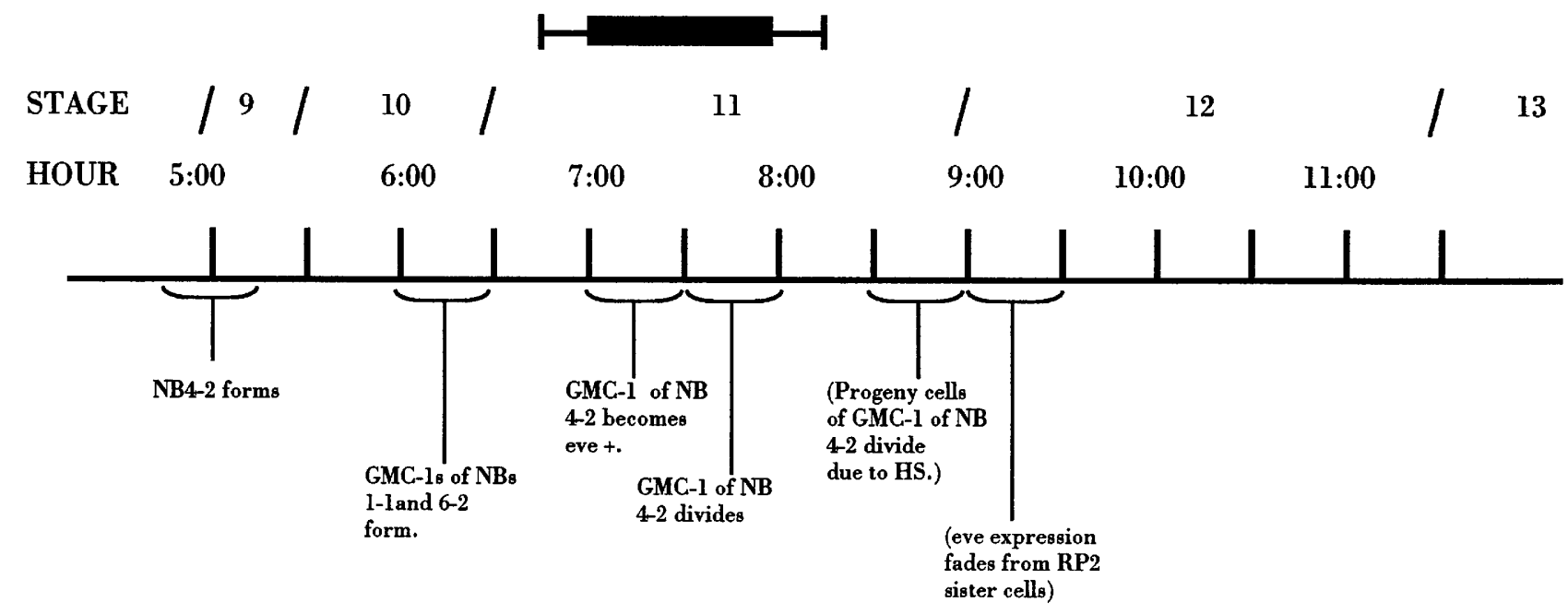

$\begin{array}{lllllllll}\begin{array}{l}\text { Hemisegments with } \\ \text { Duplicated RP2s }\end{array} & 0 & 0 & 0 & 18 & 16 & 0 & 0 & 0 \\ \begin{array}{l}\text { Hemisegments } \\ \text { Observed }\end{array} & 54 & 36 & 42 & 66 & 66 & 42 & 42 & 60\end{array}$

Figure 6. The temporal requirement of a 10-min heat shock necessary to cause RP2 duplication. The timing of the early events in the development of NB4-2 lineage is shown schematically. Embryos homozygous for the HSP70/dPOU28 transgene were obtained using a $30-\mathrm{min}$ collection and aged for various times at $25^{\circ} \mathrm{C}$. Half of the embryos were fixed, stained with anti-eve, and examined. The rest of the sample was subjected to a 10 -min heat shock at $37^{\circ} \mathrm{C}$ and aged to approximately stage 14 , stained with anti-eve, and scored for RP2 duplication. Note that the growth rate of this stock at $25^{\circ} \mathrm{C}$ is $\sim 80 \%$ of wild type; for example the presence of the eve-positive GMC-1 in wild-type animals occurs at $\sim 6 \mathrm{hr}$, whereas its appearance in this stock occurs at $\sim 7.5 \mathrm{hr}$. The temporal window during which a 10-min heat shock results in RP2 duplication in a large proportion of thoracic hemisegments is indicated by the solid bar. The data used are shown below the time line. (for details, see text).

ond, it is possible that cells within the lineage of neighboring NBs, as a result of ectopic expression of dPOU28/ pdm-2, adopt the fate of GMC-1 of NB4-2 or transiently express eve. This cannot be ruled out; however, the temporal synchrony and physical proximity of the eve-positive cells derived from the NB4-2 lineage following ectopic dPOU $28 / \mathrm{pdm}-2$ expression make this unlikely. Third, our results do not rule out the possibility that ectopic dPOU $28 / \mathrm{pdm}-2$ expression causes a further round of cell proliferation in the GMC-1 lineage. In this scenario, GMC-1 divides to generate the postmitotic RP2 and RP2 sister cell, each of which divides to reproduce itself. The use of a lineage tracer will be necessary to prove our preferred model.

\section{POU factors and the regulation of DNA replication}

The cell fate transformations induced by ectopically expressed dPOU28/pdm-2 protein cause two cells (the postmitotic RP2 and its sister cell), which no longer divide, to adopt the fate of a cell (GMC-1) that undergoes a further round of division. This clearly argues that $d P O U 28 / p d m-2$, presumably as a consequence of its role in specifying GMC-1 cell identity, plays at least an indirect role in regulating DNA replication and cell division. From the perspective of DNA replication and cell division, our findings offer an interesting functional parallel with several mammalian POU genes.
A number of POU domain proteins, in addition to being transcription factors, have also been implicated as having direct or indirect roles in regulating DNA replication. For example, both Oct-1 and Oct- 2 are capable of enhancing adenovirus DNA replication in in vitro assay systems (O'Neill et al. 1988; Verrijzer et al. 1990). In this regard, it is interesting to note the high sequence conservation between the dPOU $28 / \mathrm{pdm}-2$, Oct- 1 , and Oct- 2 POU domains (Billin et al. 1991; Dick et al. 1991; Lloyd and Sakonju 1991). The octamer-binding POU protein Tst-1/SCIP/Oct- 6 is expressed in proliferating but not terminally differentiated Schwann cells (Monuki et al. 1990). The POU protein Oct-3/Oct-4/NF-A3 (Okamoto et al. 1990; Rosner et al. 1990; Scholer et al. 1990) is expressed in embryonic stem cell line P19 only under conditions that permit cell proliferation. In addition, a large number of mammalian POU proteins appear to have an earlier, embryonic phase of expression in regions harboring proliferating progenitor cells (He et al. 1989). Taken together, these observations raise the possibility that many POU proteins, in addition to acting as transcription factors in a restricted sets of terminally differentiated cells, may also play an earlier role in regulating proliferation/DNA replication in progenitor cells.

POU genes and the development of blast cells

A number of mammalian (for review, see Rosenfeld 1991; Ruvkun and Finney 1991), Caenorhabditis (Finney 

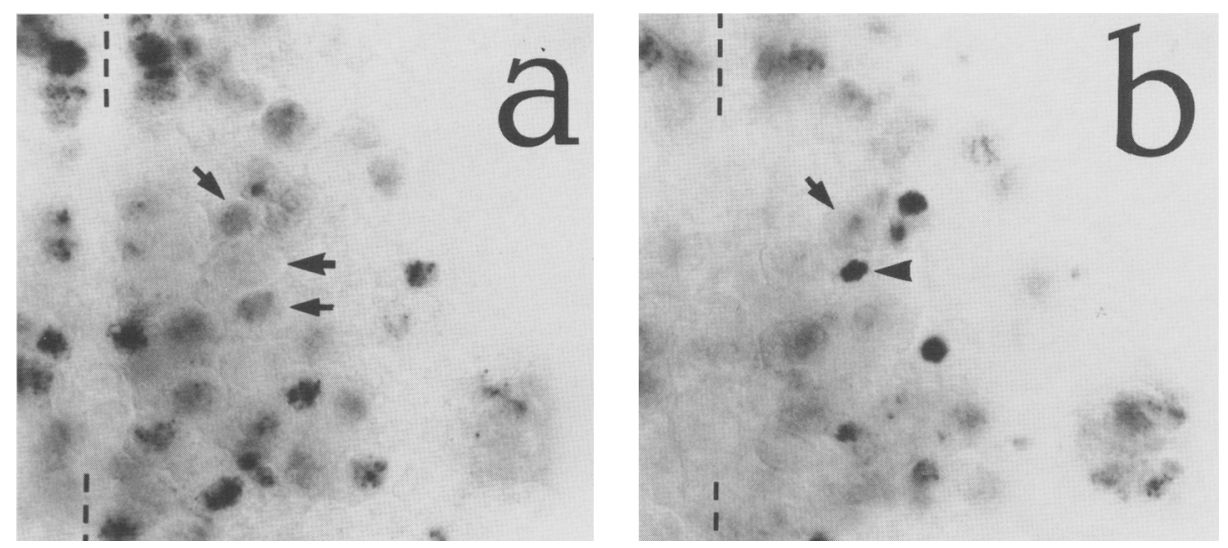

Figure 7. dPOU28/pdm-2 protein is expressed in a subset of NBs and GMCs, including GMC-1 of NB4-2. $|a, b|$ Ventral views of the same stage 11 embryos stained with anti-dPOU28 at two focal planes; midline is indicated by a broken line; anterior is toward the top. (a) The embryo is focused primarily on the plane of the NBs. NB4-2, which does not express dPOU28/pdm-2, is indicated by the large arrow; NB3-2 and NB5-3, which do express dPOU28/pdm-2, are indicated by small arrows (note the nuclear staining). (b) The same hemisegment focused on a more dorsal plane to see the GMCs more clearly. The nucleus of the GMC-1 (arrowhead) of NB4-2 located immediately dorsal to NB4-2 is stained intensely; NB3-2, which can still be seen at this more dorsal focal plane, is indicated by the arrow. Many embryos have been observed, and the assignment of the GMC-1 of NB4-2 is unambiguous. Anti-dPOU28 antibody also stains a number of other NBs and GMCs.

and Ruvkun 1990), and Drosophila (Johnson and Hirsch 1990; Billin et al. 1991; Dick et al. 1991; Lloyd and Sakonju 1991; Treacy et al. 1991, 1992) POU domain genes show spatially restricted patterns of expression, with many being expressed in the nervous system. However, only for pit-1/GHF1 and unc-86 is there any information pertaining to genetic function. It is particularly interesting to note the similarities between the nematode unc86 gene and $d P O U 28 / p d m-2$. In Caenorhabditis elegans, unc-86 is required in several NB lineages to differ-

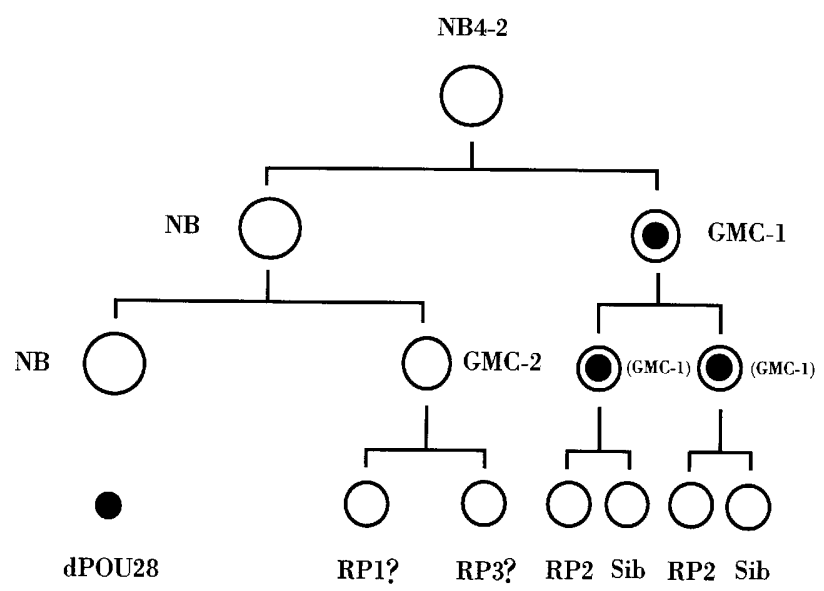

Figure 8. A schematic representation of the altered NB4-2 lineage following ectopic expression of $d P O U 28 / p d m-2$. In wildtype animals GMC-1 expresses high levels of dPOU28/pdm-2 protein, but its progeny do not. However, if dPOU $28 / \mathrm{pdm}-2$ protein is ectopically induced in the GMC-1 progeny, they both adopt the fate of GMC-1. The consequence of these cell fate transformations on the NB4-2 lineage is depicted in the diagram (for details, see text). entiate the daughter cells from their mothers; in the absence of unc-86 function, the daughter cells take on the characteristics of their NB mothers. In several NB lineages, this gene is expressed asymmetrically in one of the two NB progeny. It is not known whether unc-86 is merely required or whether it plays an active role in specifying the fate of the NB progeny. Our data on the expression and function of $d P O U 28 / p d m-2$ in the NB4-2 lineage show several parallels with the unc- 86 situation; the $d P O U 28 / p d m-2$ protein is expressed asymmetrically in one of the two NB progeny; it appears to play an active role in specifying GMC-1 identity, making it different from its daughters. Similarly Pit-1/GHF1 also appear to be required for the growth of pituitary blast cells. Therefore, all three POU genes (unc-86, pit-1/GHF1, and $d P O U 28 / p d m-2$ ), for which there exists information regarding in vivo function, appear to play a role in the development of blast cells.

\section{The role of dPOU28/pdm-2 in the context of Drosophila CNS development}

That the dPOU28/pdm-2 protein contains a putative DNA-binding POU domain and is located in the cell nucleus supports the notion that its function is effected through its action as a transcription regulator. It appears that the expression of important master transcription regulators in different spatial and temporal contexts is a common strategy adopted for the generation of cell diversity in a variety of developmental systems. Doe (1992a) has proposed that in the developing CNS, genes are expressed regionally in the neurogenic region that provide positional cues; in response to these cues, a set of NB identity genes are expressed in overlapping subsets of NBs. Within any given NB is a unique combination of 
these gene products and through their combinatorial action, a unique NB identity (and lineage) is determined. The identities of GMCs and neurons are specified by a set of GMC and neuronal identity genes, which are expressed in subsets of GMCs in response to the NB identity genes. The great majority of the candidate specification genes encode transcription factors; however, very few genes have actually been shown to be involved in specifying neural cell fate during CNS development (see introductory section). Within the context of this model, $d P O U 28 / p d m-2$ acts as a GMC identity gene, which specifies the identity of GMC-1 in the NB4-2 lineage. Because in addition to the NB4-2 lineage, dPOU28/ pdm-2 protein is also expressed in $\sim 13$ identified NBs and a similar number of GMCs per hemisegment (S. Yeo et al., unpubl.,$d P O U 28 / p d m-2$ may play a more general role in the specification of cell fate involving other NB lineages.

The genes important for the formation of the NBs / the neurogenic and proneural genes) have largely been identified and analyzed extensively. However, understanding the mechanisms by which the diversity of CNS neuronal cell types are generated requires the identification of additional genetic elements involved in specifying the unique identities of each $\mathrm{NB}$, their derivative secondary neuronal stem cells, the GMCs, and neurons. Like $\mathrm{ftz}$ and eve, $\mathrm{dPOU} 28 / \mathrm{pdm}-2$ protein is expressed in a subset of GMCs and acts to specify GMC identity. Interestingly, $d P O U 28 / p d m-2$ RNA (Lloyd and Sakonju 1991) and protein (S. Yeo, unpubl.) also show an earlier pairrule-like pattern of expression at and shortly after cellular blastoderm; however, the functional significance of this expression pattern is unclear at present. Our results clearly implicate the POU homeo domain gene dPOU28/ $p d m-2$ as a member of the growing family of genes that act to specify neural cell fate.

\section{Materials and methods}

\section{Standard molecular biology techniques}

DNA sequencing was performed by the chain-termination method with Sequenase (U.S. Biochemical). Southern hybridization and all routine DNA work was performed as described by Sambrook et al. (1989).

\section{Antibody preparation}

A fusion protein containing amino acid residues 19-212 from the nonconserved amino-terminal portion of the deduced dPOU28/pdm-2 protein was produced in Escherichia coli using a modified pGEX vector (Guan and Dixon 1991). The fusion protein was affinity purified using glutathione-Sepharose beads and injected into rabbits. Purified fusion protein $(100 \mu \mathrm{g})$ was used for the initial inoculation (complete Freund's adjuvant) and subsequent boosts (incomplete Freund's adjuvant). Serum was affinity purified using the low $\mathrm{pH}$ method described by Sambrook et al. (1989).

\section{Immunocytochemistry and photomicroscopy}

Single-antibody staining was performed essentially as described by Yang et al. (1991). Embryos were collected, dechorionated with $50 \%$ bleach, fixed with $4 \%$ paraformaldehyde for $30 \mathrm{~min}$, devitellinized with a $1: 1$ mixture of heptane/methanol, washed with methanol, and rehydrated with PBT. Anti-eve and anti-ftz were rabbit polyclonal serums [gifts of Manfred Frasch (Mount Sinai Medical Center) and the Gehring laboratory, respectively]; anti-fasciclin III (mAb2D5) was a gift of the Goodman laboratory (University of California, Berkeley); 22c10 was a gift from J. Campos-Ortega (University of Cologne, Germany).

The mAb2D5 stainings were performed using dissected embryos in the absence of detergent. Double-labeling was performed essentially as described by Kania et al. (1990). Following color development with the first antibody, the embryos were washed in $0.2 \mathrm{M}$ glycine $(\mathrm{pH} 2.5)$ for $5 \mathrm{~min}$. Embryos were washed with $\mathrm{PBT}$ and reblocked with $1 \% \mathrm{BSA}$, and secondantibody reactions were performed. Normally we use nickelcoupled DAB reaction for the first color development (black); the second color reaction was performed in the absence of nickel (brown). Photomicrographs were taken with a Zeiss Axiophot using DIC optics and either a $63 \times$ Planapo or a $20 \times$ Neofluor lens.

\section{Heat shock construct}

The BamHI site in the polylinker of the shuttle vector pHSX (gift from Rubin laboratory, referred to in Moses et al. 1989) was removed by cutting with BamHI, filling in the cohesive ends with Klenow, and religating the blunt ends. The XhoI-Sall fragment of the plasmid hspXS (gift from Susan Parkhurst, California Institute of Technology, Pasadena), containing the HSP7O promoter along with a downstream $B a m H I$ site, was cloned into the modified shuttle vector. The resultant plasmid was linearized with $B a m H I$, and blunt ends were produced with Klenow; a HindIII-EcoRI fragment containing a full-length dPOU28/ pdm-2 cDNA isolated from an embryonic cDNA library (Brown and Kafatis 1988) was blunt ended and inserted in the appropriate orientation into the filled-in BamHI site. From the resultant plasmid, the HSP70/dPOU28 gene was excised using NotI and cloned into the NotI site of the Drosophila germ-line transformation vector pCaWc (referred to in Moses et al. 1989).

\section{Germ-line transformation}

The procedure described by Spradling (1986) was used to obtain germ-line transformants. Preblastoderm rosy ${ }^{506}\left(\right.$ ry $\left.^{506}\right)$ embryos obtained from 45-min collections were dechorionated in 50\% bleach, $0.01 \%$ Triton- X-100, and arranged in rows of $\sim 50$ on a black nitrocellulose filter disc, with all of the posterior ends facing the same direction; the embryos were transferred to a coverslip made sticky using gum extracted from Scotch tape with their posterior ends facing the edge of the coverslip. The embryos were dessicated for between 11 and $15 \mathrm{~min}$ by placing the coverslip in an air-tight plastic box filled with dessicant. After immersion in hydrocarbon oil (Voltalef), the embryos were injected near their posterior end with a $500 \mu \mathrm{g} / \mathrm{ml}$ solution of the HSP70/dPOU28 construct in pCaWc. It was not necessary to coinject a plasmid to supply the P-element transposase because this construct already contains the P-element transposase gene in the portion of the molecule outside of the P-element inverted repeats. Injected embryos were allowed to develop at $22^{\circ} \mathrm{C}$, and surviving adults were individually mated to $\mathrm{ry}^{506}$ flies. Progeny with $\mathrm{ry}^{+}$eye color were obtained. Balanced stocks were established, and genomic blots were performed to ascertain the integrity, as well as the number, of inserts. heat shocks were performed for $10 \mathrm{~min}$ at $37^{\circ} \mathrm{C}$. 


\section{Staging embryos}

In general, we use the morphological criteria set out by CamposOrtega and Hartenstein (1985). Figure 5 depicts a real sequence of events rather than a plausible sequence of events. There are two independent criteria that we use to stage embryos. The easiest one is the state of the anti-eve staining pattern. evepositive cells first appear in the GMC-1 of NBl-1 and NB6-2 (late stage 10, early stage 11), followed by the GMC-1 of NB4-2 at mid-stage 11 . During these early stages, staging can also be done with the NB arrays (Doe 1992b). The GMC-1 of NB4-2 can be identified by virtue of its proximity to the parental NBs and by the fact that it also expresses eve (and $\mathrm{dPOU} 28 / \mathrm{pdm}-2$ ); NB4-2 can be unambiguously identified by position even in the absence of markers. The number of the eve-positive cells that give rise to the aCC/pCC/CQ cluster grows (up to about eight cells) during stages 11 and 12 . The EL cluster of eve-positive cells first becomes evident as one or two cells during the middle of stage 12 and eventually increases to $\sim 10$ cells in the abdominal segments and $\sim 6$ cells in the thoracic segments. The size of the EL cluster reflects the relative age of the embryos from stage 12 onward.

\section{Acknowledgments}

We thank the Goodman laboratory for the anti-fasciclin III (mAb2D5) and anti-en (mAb4D9) antibodies; Corey Goodman for some helpful advice on the NB4-2 lineage; Manfred Frasch for the anti-eve polyclonal serum; the Gehring laboratory for the anti-ftz serum; and the Campos-Ortega laboratory for mAb22C10. We thank Nick Brown for his superb cDNA banks; John Tamkun for genomic libraries; Susan Parkhurst for plasmids containing the HSP70 promoter; and the Rubin laboratory for plasmids pHSX and pCaWc. We are grateful to C.Q. Doe for his generosity with unpublished information and for his thoughts and advice. We thank Catherine Pallen, David Murphy, Nam Hai Chua, Katrin Weigmann, and members of our laboratory for discussion and comments on the manuscript. We thank Chris Tan for his encouragement and the Institute of Molecular and Cell Biology and the European Community (an ASEAN/EC cooperative grant) for financial support.

The publication costs of this article were defrayed in part by payment of page charges. This article must therefore be hereby marked "advertisement" in accordance with 18 USC section 1734 solely to indicate this fact.

\section{References}

Artavanis-Tsakonas, S. and P. Simpson. 1991. Choosing a cell fate: A view from the Notch locus. Trends Genet. 7: 403408.

Billin, A.N., K.A. Cockerill, and S.J. Poole. 1991. Isolation of a family of Drosophila POU domain genes expressed in early development. Mech. Dev. 34: 75-84.

Blochlinger, K., R. Bodmer, L.Y. Jan, and Y.N. Jan. 1990. Patterns of expression of Cut, a protein required for external sensory organ development in wild type and cut mutant Drosophila embryos. Genes \& Dev. 4: 1322-1331.

Blochlinger, K., L.Y. Jan, and Y.N. Jan. 1991. Transformation of sensory organ identity by ectopic expression of cut in Drosophila. Genes \& Dev. 5: 1124-1135.

Bodmer, R., S. Barbel, S. Shepherd, J.W. Jack, L.Y. Jan, and Y.N. Jan. 1987. Transformation of sensory organs by mutations of the cut locus of Drosophila melanogaster. Cell 51: 293-307.

Brown, N.H. and F.C. Kafatis. 1988. Functional Drosophila
cDNA libraries from Drosophila embryos. I. Mol. Biol. 203: 425-437.

Campos-Ortega, J.A. 1990. Mechanisms of a cellular decision during embryonic development of Drosophila melanogaster: Epidermogenesis or neurogenesis. Adv. Genet. 27: 403-453.

Campos-Ortega, J.A. and V. Hartenstein. 1985. The embryonic development of Drosophila melanogaster. Springer-Verlag, Berlin, Germany.

Campuzano, S. and J. Modolell. 1992. Patterning of the Drosophila nervous system: The achaete-scute gene complex. Trends Genet. 6: 202-208.

Carroll, S.B. and M.P. Scott. 1985. Localisation of fushi tarazu protein during Drosophila embryogenesis. Cell 43: 47-57.

Caudy, M., H. Vaessin, M. Brand, M. Tuma, L.Y. Jan, and Y.N. Jan. 1988. daughterless, a Drosophila gene essential for both neurogenesis and sex determination, has sequence similarities to myc and the achaete-scute complex. Cell 55: 10611067.

Dambly-Chaudiere, C., E. Jamet, M. Burri, D. Bopp, K. Basler, E. Hafen, N. Dumont, P. Spielmann, A. Ghysen and M. Noll. 1992. The paired box gene pox neuro: A determinant of polyinnervated sense organs in Drosophila. Cell 69: 159-172.

Dick, T., X. Yang, S. Yeo, and W. Chia. 1991. Two closely linked Drosophila POU domain genes are expressed in neuroblasts and sensory elements. Proc. Nat1. Acad. Sci. 88: 7645-7649.

Doe, C.Q. 1992a. The generation of neuronal diversity in the Drosophila central nervous system. In Determinants of neuronal identity (ed. M. Shankland and E. Macagno), pp. 119154. Academic Press, New York.

_ 1992b. Molecular markers for identified neuroblasts and ganglion mother cells in the Drosophila central nervous system. Development 116: 855-863.

Doe, C.Q. and C.S. Goodman. 1985. Early events in insect neurogenesis. II. The role of cell interactions and cell lineages in the determination of neuronal precursor cell. Dev. Biol. 111: 206-219.

Doe, C.Q. and D.T. Smouse. 1990. The origins of cell diversity in the insect central nervous system. Sem. Cell Biol. 1: 211218.

Doe, C.Q., Y. Hiromi, W. Gehring, and C.S. Goodman. 1988a. Expression and function of the segmentation gene fushi tarazu during Drosophila neurogenesis. Science 239: 170175.

Doe, C.Q., D. Smouse, and C.S. Goodman. 1988b. Control of neuronal fate by the Drosophila segmentation gene evenskipped. Nature 333: 376-378.

Doe, C.Q., Q. Chu-Lagraff, D.M. Wright, and M.P. Scott. 1991. The prospero gene specifies cell fates in the Drosophila central nervous system. Cell 65: 451-464.

Duffy, J.B., M.A. Kania, and J.P. Gergen. 1991. Expression and function of the Drosophila gene runt in early stages of neural development. Development 113: 1223-1230.

Finkelstein, R., D. Smouse, T.M. Capaci, A.C. Spradling and N. Perrimon. 1990. The orthodenticle gene encodes a novel homeo domain protein involved in the development of the Drosophila nervous system and ocellar visual structures. Genes \& Dev. 4: 1516-1527.

Finney, M. and G. Ruvkun. 1990. The unc-86 gene product couples cell lineage and cell identity in C. elegans. Cell 63: 895905.

Frasch, M., T. Hoey, C. Rushlow, H. Doyle, and M. Levine. 1987. Characterisation and localisation of the even-skipped protein of Drosophila. EMBO J. 6: 749-759.

Fujita, S., S.L. Zipursky, S. Benzer, A. Ferrus, and S.L. Shotwell. 1982. Monoclonal antibodies against the Drosophila nervous system. Proc. Natl. Acad. Sci. 79: 7929-7933. 
Gaul, U., E. Seiffert, R. Schuh, and H. Jackle. 1987. Analysis of Kruppel protein distribution during early Drosophila development reveals post-transcriptional regulation. Cell 50: 639-647.

Ghysen A. and C. Dambly-Chaudiere. 1989. Genesis of the Drosophila peripheral nervous system. Trends Genet. 5: 251-255.

Guan, K. and J.E. Dixon. 1991. Eucaryotic proteins expressed in E. coli: An improved thrombin cleavage and purification procedure for fusion proteins with glutathione S-transferase. Anal. Biochem. 192: 262-267.

He, X., M. Treacy, D. Simmons, H. Ingraham, L. Swanson, and M. Rosenfeld. 1989. Expression of a large family of POUdomain regulatory genes in mammalian brain development. Nature 340: 35-42.

Herr, W., R.A. Sturm, R.G. Clerc, L.M. Corcoran, D. Baltimore, P.A. Sharp, H.A. Ingraham, M.G. Rosenfeld, M. Finney, G. Ruvkun, and H.R. Horvitz. 1988. The POU domain: A large conserved region in the mammalian pit-1, oct-1, oct-2 and Caenorhabditis elegans unc-86 gene products. Genes \& Dev. 2: 1513-1516.

Hooper, J.E. and M.P. Scott. 1989. The Drosophila patched gene encodes a putative membrane protein required for segmental patterning. Cell 59: 751-765.

Huff, R., A. Furst, and A.P. Mahowald. 1989. Drosophila embryonic neuroblasts in culture: Autonomous differentiation of specific transmitters. Dev. Biol. 134: 146-157.

Jan, L.Y. and Y.N. Jan. 1991. Genes required for specifying cell fates in Drosophila embryonic sensory nervous system. Trends Neurosci. 13: 493-498.

Jimenez, F. and J.A. Campos-Ortega. 1990. Defective neuroblast commitment in mutants of achaete-scute complex and adjacent genes of $D$. melanogaster. Neuron 5: 81-89.

Johnson, W.A. and J. Hirsch. 1990. Binding of a Drosophila POU-domain protein to a sequence element regulating gene expression in specific dopaminergic neurons. Nature 343: 467-470.

Kania M.A., A.S. Bonner, J.B. Duffy, and J.P. Gergen. 1990. The Drosophila segmentation runt encodes a novel nuclear protein that is also expressed in the developing nervous system. Genes \& Dev. 4: 1701-1713.

Klambt, C., J.R. Jacobs, and C.S. Goodman. 1991. The midline of Drosophila central nervous system: A model for the genetic analysis of cell fate, cell migration, and growth cone guidance. Cell 64: 801-815.

Lloyd, A. and S. Sakonju. 1991. Characterisation of two Drosophila POU domain genes, related to oct-1 and oct-2, and the regulation of their expression patterns. Mech. Dev. 36: 87102.

Martin-Bermudo, M.D., C. Martinez, A. Rodriguez, and F. Jimenez. 1991. Distribution and function of the lethal of scute gene product during early neurogenesis in Drosophila. Development 113: 445-454.

Mlodzik, M., Y. Hiromi, U. Weber, C.S. Goodman, and G.M. Rubin. 1990. The Drosophila seven-up gene, a member of the steroid receptor gene superfamily, controls photoreceptor cell fates. Cell 60: 211-224.

Monuki, E., R. Kuhn, G. Weinmaster, B. Trapp, and G. Lemke. 1990. Expression and activity of the POU transcription factor SCIP. Science 249: 1300-1303.

Moses, K., M.C. Ellis, and G.M. Rubin. 1989. The glass gene encodes a zinc-finger protein required by Drosophila photoreceptor cells. Nature 340: 531-536.

Nakano, Y., I. Guerrero, A. Hidalgo, A. Taylor, J.R.S. Whittle, and P.W. Ingham. 1989. A protein with several possible membrane-spanning domains encoded by the Drosophila segment polarity gene patched. Nature 341: 508-513.

Okamoto, K., H. Okazawa, A. Okuda, M. Sakai, M. Muramatsu, and H. Hamada. 1990. A novel octamer transcription factor is differentially expressed in mouse embryonic cells. Cell 60: 461-472.

O'Neill, E., C. Fletcher, C. Burrow, N. Heintz, R. Roeder, and T. Kelly. 1988. Science 241: 1210-1213.

Patel, N.H., P.M. Snow, and C.S. Goodman. 1987. Characterisation and cloning of fasciclin III: A glycoprotein expressed on a subset of neurons and axon pathways in Drosophila. Cell 48: 475-488.

Patel, N.H., B. Schafer, C.S. Goodman, and R. Holmgren. 1989a. The role of segment polarity genes during Drosophila neurogenesis. Genes \& Dev. 3: 890-904.

Patel, N.H., E. Martin-Blanco, K.G. Coleman, S. Poole, M.C. Ellis, T.B. Kornberg, and C.S. Goodman. 1989b. Expression of engrailed proteins in arthropods, annelids, and chordates. Cell 58: 955-968.

Rodrigues, I., R. Hernandez, J. Modolell, and M. Ruiz-Gomez. 1990. Competence to develop sensory organs is temporally and spatially regulated in Drosophila epidermal primordia. EMBO J. 9: 3583-3592.

Rosner, M., M. Vigano, K. Ozato, P. Timmons, F. Poirier, P.W.J. Rigby, and L.M. Staudt. 1990. A POU domain transcription factor in early stem cells and germ cells of the mammalian embryo. Nature 345: 686-691.

Rosenfeld, M.G. 1991. POU-domain transcription factors: pouer-ful developmental regulators. Genes \& Dev. 5: 897-907.

Rothberg, J.M., D.A. Hartly, Z. Walther, and S. Artavanis-Tsakonas. 1988. slit: An EGF-homologous locus of D. melanogaster involved in the development of the embryonic central nervous system. Cell 55: 1047-1059.

Ruvkun, G. and M. Finney. 1991. Regulation of transcription and cell identity by POU domain proteins. Cell 64: 475-478.

Sambrook, J., E.F. Frisch, and T. Maniatis. 1989. Molecular cloning: A laboratory manual. Cold Spring Harbor Laboratory Press, Cold Spring Harbor, New York.

Scholer, H., S. Rupert, R. Balling, H. Rohdewohld, and P. Gruss. 1990. New type of POU domain in germ line specific protein Oct-4. Nature 344: 435-439.

Schroder, C., D. Tautz, E. Seifert, and H. Jackle. 1988. Differential regulation of the two transcripts from the Drosophila gap segmentation gene hunchback. EMBO /. 7: 2881-2887.

Spradling, A.C. 1986. P-element mediated transformation. In Drosophila: A practical approach (ed. D.B. Roberts), pp. 175197. IRL Press, Oxford, England.

Thomas, J.B., M.J. Bastiani, M. Bate, and C.S. Goodman. 1984. From grasshopper to Drosophila: A common plan for neuronal development. Nature 310: 203-207.

Thomas, J.B., S.T. Crews, and C.S. Goodman. 1988. Molecular genetics of the single-minded locus: A gene involved in the development of the Drosophila nervous system. Cell 52: 133-141.

Treacy, M.N., X. He, and M.G. Rosenfeld. 1991. I-POU: A POUdomain protein that inhibits neuron-specific gene activation. Nature 350: 577-584.

Treacy, M.N., L. Neilson, E. Turner, X. He, and M.G. Rosenfeld. 1992. Twin of I-POU: A two amino acid difference in I-POU homeodomain distinguishes an activator from an inhibitor of transcription. Cell 68: 491-505.

Vaessin, H., E. Grell, E. Wolff, E. Bier, L.Y. Jan, and Y.N. Jan. 1991. Prospero is expressed in neuronal precursors and encodes a nuclear protein that is involved in the control of axon outgrowth in Drosophila. Cell 67: 941-953.

van den Heuvel, M., R. Nusse, P. Johnson, and P.A. Lawrence. 1989. Distribution of the wingless gene product in Droso- 
Yang et al.

phila embryos: A protein involved in cell-cell communication. Cell 59: 739-749.

Verrijer, C.P., A.J. Kal, and P.C. van der Vliet. 1990. The DNA binding domain (POU domain) of transcription factor Oct-1 suffices for stimulation of DNA replication. EMBO $J$. 9: 1883-1888.

Villares, R. and C.V. Cabrera. 1987. The achaete-scute gene complex of $D$. melanogaster: Conserved domains in a subset of genes required for neurogenesis and their homology to myc. Cell 50: 415-424.

Yang, X., K.T. Seow, S.M. Bahri, S.W. Oon, and W. Chia. 1991. Two Drosophila receptor-like tyrosine phosphatase genes are expressed in a subset of developing axons and pioneering neurons in the embryonic CNS. Cell 67: 661-673.

Zipursky, S.L., T. Venkatesh, D. Teplow, and S. Benzer. 1984. Neuronal development in the Drosophila retina: Monoclonal antibodies as molecular probes. Cell 36: 15-26. 


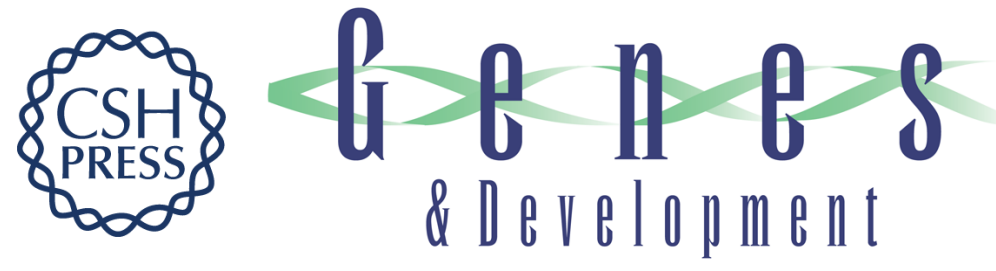

\section{The role of a Drosophila POU homeo domain gene in the specification of neural precursor cell identity in the developing embryonic central nervous system.}

$X$ Yang, $S$ Yeo, T Dick, et al.

Genes Dev. 1993, 7:

Access the most recent version at doi:10.1101/gad.7.3.504

References This article cites 63 articles, 15 of which can be accessed free at: http://genesdev.cshlp.org/content/7/3/504.full.html\#ref-list-1

License

Email Alerting Service

Receive free email alerts when new articles cite this article - sign up in the box at the top right corner of the article or click here.

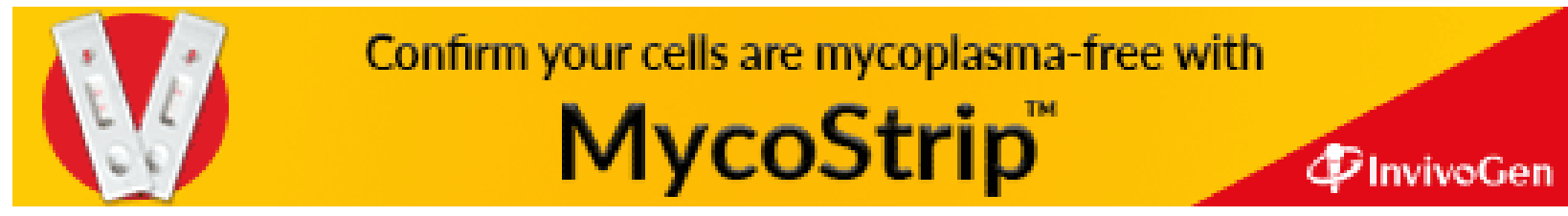

